\title{
Penggunaan Styrofoam sebagai Material Bilah Turbin Angin
}

\author{
Manty Aldilani Ikaningsih ${ }^{a}$ *, War'an Rosihan ${ }^{b}$ \\ a Jurusan Teknik Metalurgi, Fakultas Teknik, Universitas Jenderal Achmad Yani \\ Jl. Ters. Jend. Gatot Soebroto, Bandung \\ bJurusan Teknik Mesin, Fakultas Teknik, Universitas Jenderal Achmad Yani \\ Jl. Ters. Jend. Sudirman, Cimahi \\ *E-mail: manty.aldilani@lecture.unjani.ac.id
}

\begin{abstract}
In this experiment, wind turbine blades were made from wood and styrofoam with the aim that at a certain speed the blades can be damaged. This damage is centered on the part of styrofoam which has a level of resistance under the wood loading. Damage to the blade will protect the generator from over speeding. In this study, the design of the wind turbine blades used came from the Lentera Angin Nusantara. The wind turbine blades made are a taperless type, where the same blade size from base to tip. Modification of wind turbine blades is based on the simulation results of the performance of wind turbine blades using QBlade. In the simulation, it is shown that the biggest contribution to the total torque value comes from the elemental torque of the blade section at the position of 50\% - 100\% the length of the blade. Based on the simulation results of the performance of the wind turbine blades, the wind turbine blades made from wood base material are modified from the middle to the back end using styrofoam. The hope is that this modification will prevent over speed on the generator and focus the damage on parts of styrofoam blades due to thrust when the wind speed is quite high. If the field test is successful, then the location of the blade failure will minimize damage (broken) the blade in the unpredictable part.
\end{abstract}

Keywords: wind turbine blades, taperless, styrofoam, QBlade

\begin{abstract}
Abstrak
Percobaan pembuatan bilah turbin angin dengan bahan kayu dan styrofoam dilakukan dengan tujuan agar pada kecepatan tertentu bilah dapat rusak. Kerusakan ini dipusatkan pada bagian styrofoam yang memiliki tingkat ketahanan pembebanan di bawah kayu. Kerusakan bilah tersebut nantinya akan melindungi generator agar tidak mengalami overspeed. Pada penelitian ini, desain bilah turbin angin yang digunakan berasal dari lembaga penelitian Lentera Angin Nusantara. Bilah turbin angin yang dibuat adalah tipe taperless, dimana ukuran bilah sama dari pangkal hingga ujung. Modifikasi bilah turbin angin dilakukan berdasarkan hasil simulasi performa bilah turbin angin dengan menggunakan perangkat lunak QBlade. Pada hasil simulasi ditunjukkan bahwa sumbangsih terbesar harga torsi total berasal dari torsi elemental dari bagian bilah pada posisi 50\% - 100\% panjang bilah. Berdasarkan hasil simulasi performa bilah turbin angin tersebut, maka bilah turbin angin yang dibuat dari bahan dasar kayu dimodifikasi dari bagian tengah hingga bagian ujung belakang dengan menggunakan styrofoam. Harapannya modifikasi tersebut akan mencegah overspeed pada generator dan memusatkan kerusakan di bagian bilah yang terbuat dari styrofoam akibat gaya dorong saat kecepatan angin cukup tinggi. Jika uji lapangan berhasil, maka pemusatan letak kegagalan bilah akan meminimalisir kerusakan (patahnya) bilah di bagian yang tidak terprediksi.
\end{abstract}

Kata kunci: bilah turbin angin, taperless, styrofoam, QBlade

\section{Pendahuluan}

Angin merupakan alternatif sumber energi terbarukan yang sangat potensial karena tersedia bebas di alam dan ramah lingkungan. Energi listrik dihasilkan dari angin dengan bantuan turbin angin menggunakan prinsip konversi energi. Angin menggerakkan bilah turbin angin, sehingga poros turbin berputar. Turbin angin terdiri dari bilah-bilah yang terpasang ke sebuah poros. Selanjutnya, poros dihubungkan ke generator, kemudian ke baterai yang berfungsi sebagai penyimpan energi. Dalam hal ini, generator berfungsi mengubah energi mekanik menjadi energi listrik.

Potensi angin di Indonesia sangat besar untuk dikembangkan sebagai alternatif sumber energi terbarukan. Indonesia memiliki total garis pantai mencapai $81.000 \mathrm{~km}$ dengan kecepatan angin rata-rata $3-5 \mathrm{~m} / \mathrm{s}$, bahkan mencapai $10 \mathrm{~m} / \mathrm{s}$ di beberapa daerah. Distribusi kecepatan angin di Indonesia dapat dilihat di Gambar 1. 


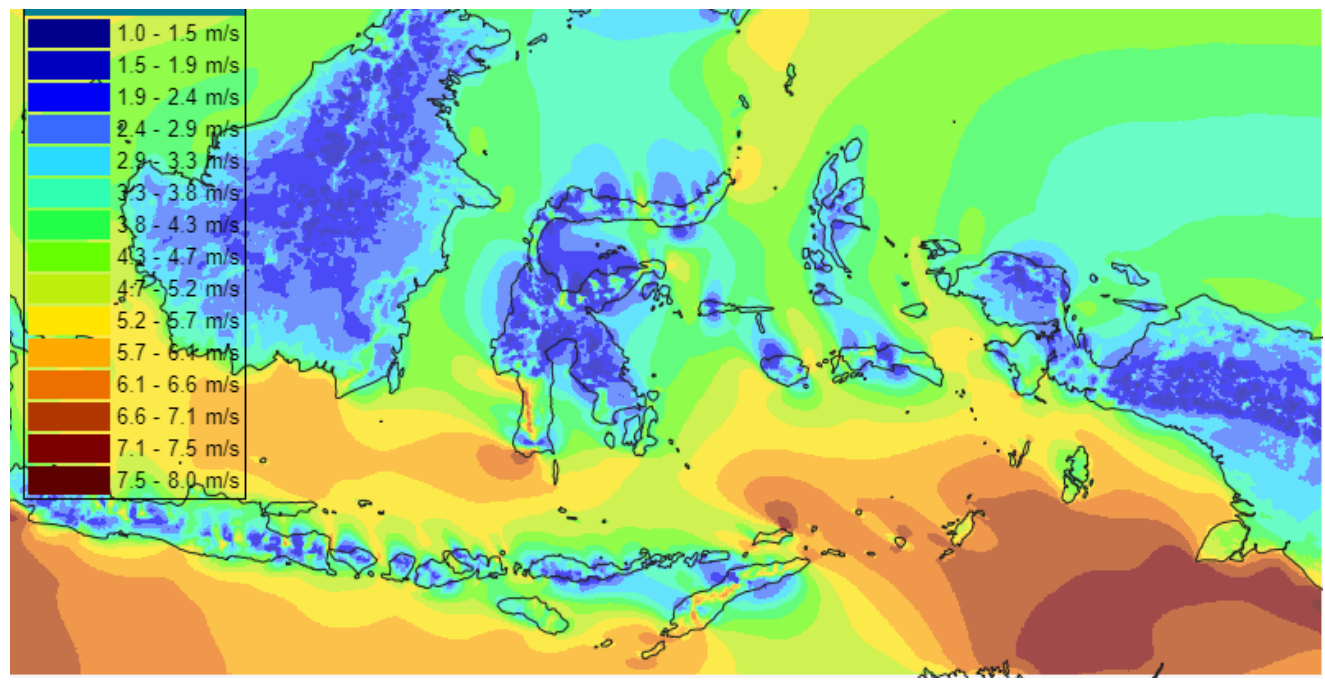

Gambar 1. Peta kecepatan angin di Indonesia [1]

Manty dan Deny memodelkan bilah turbin angin jenis taperless dengan lebar penampang bilah dari pangkal ke ujung seragam sebesar $0.05 \mathrm{~m}$. Bilah ini dibuat dengan menggunakan material batang Carbon Fiber Reinforced Plastic (CFRP), Expandable Polystyrene (ES) dan lembaran vinil (vinyl sheet). Bagian inti bilah dibuat dari EPS yang disisipi dengan dua batang CFRP berpenampang $2 \mathrm{~mm}$. Bagian permukaan bilah dilapisi dengan lembaran vinil. Hasil simulasi FEA menunjukkan bahwa tegangan von Mises maksimum sebesar 473,3 MPa terjadi pada bagian CFRP. Oleh karena itu, dilakukanlah mofidikasi terhadap batang CFRP tersebut dengan mengganti ukuran diameter $2 \mathrm{~mm}$ menjadi $3 \mathrm{~mm}$. Terbukti dengan menambahkan ukuran batang CFRP, tegangan Von Mises maksimum berkurang menjadi 60,45 MPa. Selain itu, faktor keamanan bilah pun meningkat menjadi 4,96, kurang lebih 8x lipat dari kondisi sebelum dimodifikasi [2].

Chandra Sekhar (2014) merancang dan membuat bilah turbin angin untuk menghasilkan energi sebesar 375 Watt. Penelitian tersebut bertujuan untuk mengembangkan turbin angin domestik yang bekerja pada kecepatan angin rendah dan dapat digunakan oleh "orang biasa" dengan biaya rendah. Kayu jati (teak wood) digunakan untuk membuat bilah dan hub turbin angin karena mudah didapat. Dalam proses perancangan bagian airfoil harus dipertimbangkan berbagai gaya yang bekerja pada bilah, seperti gaya axial, gaya angkat dan gaya dorong. Gaya-gaya tersebut harus diperhitungkan secara teoritis dan desain dioptimalkan untuk mendapatkan output daya optimum [3].

Maldhure (2013) menguji kelelahan bilah turbin angin yang terbuat dari kayu sepanjang $1.5 \mathrm{~m}$ dengan menggunakan rig uji. Rig menggunakan mekanisme engkol eksentrik dengan beban variabel untuk setiap beban. Distribusi tegangan pada area kritis lelah bilah sama dengan distribusi tegangan yang diharapkan pada kondisi operasi normal. Pada umumnya, kegagalan bilah turbin angin adalah $7 \%$ dari total komponen yang tersedia pada generator turbin angin. Namun pada prakteknya, ketika bilah turbin angin gagal dalam kondisi berjalan, maka total sistem generator turbin angin collapse dan perkiraan biaya generator turbin angin $90 \%$ akan terbuang. Keuntungan dari kayu jati (teak wood), kayu pinus dan kayu cemara antara lain mudah didapat, biaya bahan rendah, tidak mengakibatkan pencemaran terhadap lingkungan, ringan dan memiliki kekuatan yang tinggi untuk generator bilah turbin angin kecil. Adapun keterbatasan dari material tersebut adalah sulit membentuk bilah dalam bentuk aerodinamis dan biaya pembuatan bilah setara dengan biaya material. Dalam penelitian ini disimpulkan bahwa kayu masih merupakan material terbaik untuk bilah turbin angin dengan ukuran mikro dan mini [4].

Sudarsono (2012) membuat prototipe propeler airfoil standard NACA 4415 modifikasi dengan memanfaatkan kayu sengon laut dan serat rami. Komposit serat rami dengan core kayu sengon laut dibuat dengan proses hand lay up 2 lapis. Tegangan tekuk komposit yang dihasilkan sebesar 45,663 MPa dengan modulus Young 1,244 GPa dan regangan 1,795 \% [5].

Chang, R. R., et.al. (2011) membuat bilah turbin angin dari material komposit dengan menumpuk serat gelas dan busa expandable polystyrene (EPS) melalui proses resin transfer molding (RTM) dan compression molding. Bilah turbin dibuat dengan struktur sandwich yang terdiri dari busa komposit di bagian dalam (inti) dan serat pada bagian luar sebagai penguatnya. Hasil penelitian menunjukkan bahwa ikatan yang terbentuk antara interface busa EPS - serat cukup kuat [6].

Simon Jupp (2011) menyatakan bahwa alumunium merupakan alternatif yang baik untuk turbin angin lepas pantai (offshore). Hal tersebut karena alumunium memiliki berat yang ringan, tahan terhadap api, mudah diinspeksi, nilai konduktivitas termal tinggi, dapat di-recycle, dan permukaannya dapat diproses lagi [7].

Bilah turbin angin harus dibuat dengan struktur yang ringan dan stabil. Selain itu, bilah turbin angin pun harus cukup mampu menahan angin dengan kecepatan tinggi. Akan tetapi, bilah turbin yang terlalu kuat dan stabil dapat mengakibatkan kerusakan pada generator. Untuk mengatasi hal tersebut, maka dibuatlah modifikasi bilah turbin angin dengan menggunakan styrofoam. Dengan modifikasi tersebut, diharapkan nantnya bagian yang rusak atau patah dari turbin angin adalah bilah bagian ujung, bukan bagian pangkal apalagi generatornya. 


\section{Material dan metode penelitian}

A. Perancangan Desain dan Dimensi Bilah Turbin Angin

Desain bilah turbin angin yang digunakan dalam penelitian ini berasal dari lembaga penelitian Lentera Angin Nusantara, ditunjukkan dalam Gambar 2. Bilah turbin angin yang dibuat adalah tipe taperless, dimana ukuran bilah sama dari pangkal hingga ujung.

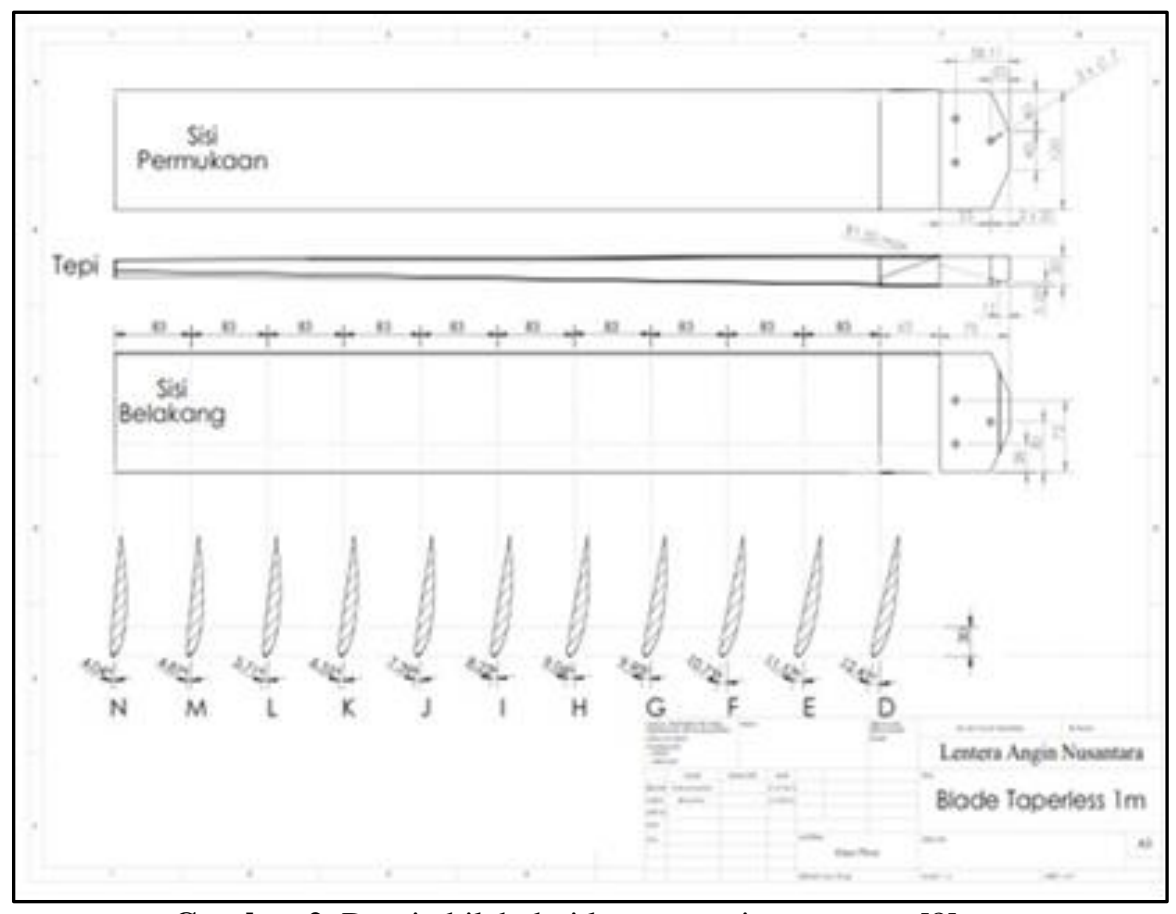

Gambar 2. Desain bilah dari lentera angin nusantara [8]

Untuk memodifikasi struktur bilah turbin angin, terlebih dahulu dilakukan analisa aerodinamis. Gambar 3 menunjukkan gambar geometri desain bilah turbin angin yang dibuat sesuai dengan gambar teknis dari Lentera Angin Nusantara.

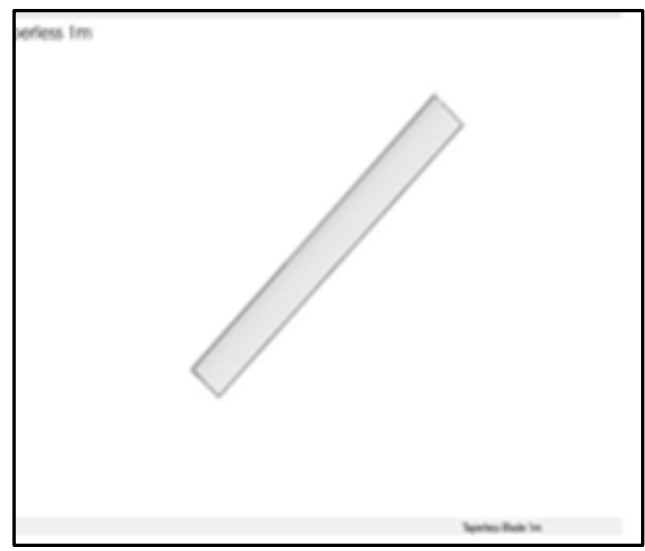

Gambar 3. Desain bilah taperless di Qblade V0.91b

Selanjutnya dilakukan simulasi performa bilah turbin angin dengan menggunakan perangkat lunak QBlade. QBlade merupakan perangkat lunak open source yang digunakan untuk simulasi dan perancangan turbin angina [9]. Hasil simulasi QBlade berupa grafik yang menunjukkan parameter-parameter penting yang mempengaruhi performa bilah, antara lain daya, torsi, kecepatan angin, kecepatan putaran dan efisiensi dari bilah tersebut [10].

Gambar 4 menunjukkan hasil simulasi performa dari rancangan bilah turbin angin. Dari hasil simulasi tersebut, terlihat bahwa sumbangsih terbesar harga torsi total dari rancangan bilah turbin ini berasal dari torsi elemental dari bagian bilah pada posisi $50-100 \%$ panjang bilah. 


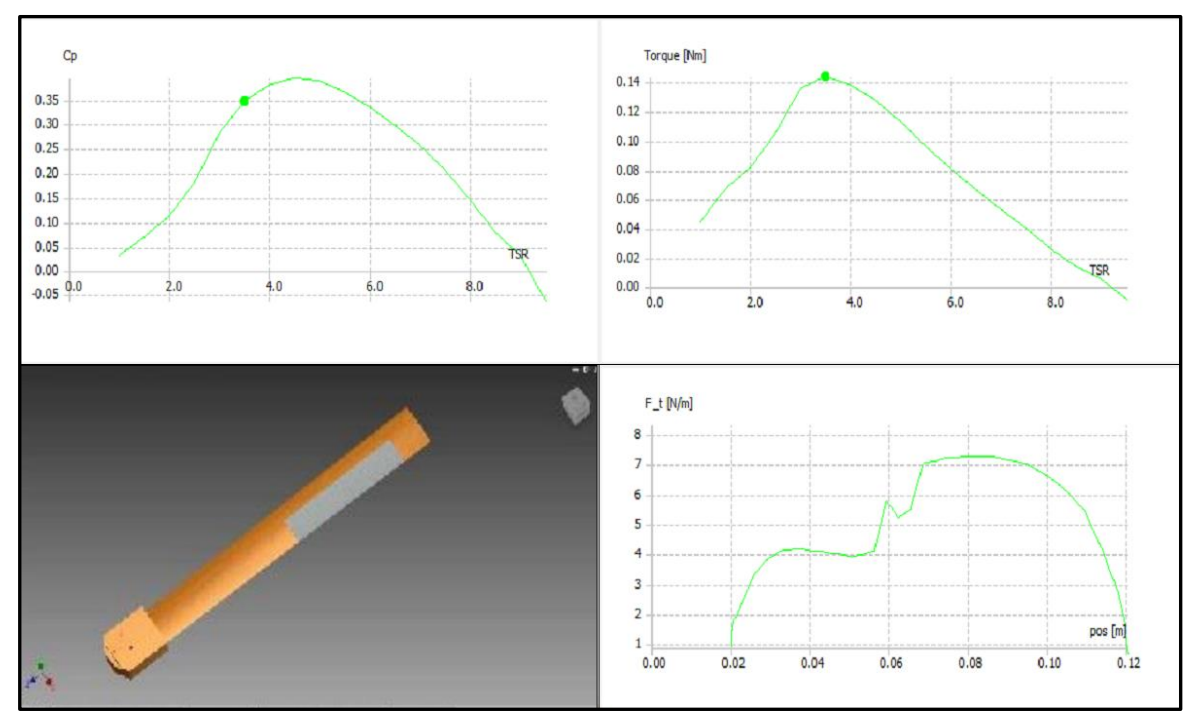

Gambar 4. Performa bilah turbin dan pembebanannya

Berdasarkan hasil simulasi performa bilah turbin angin tersebut, maka bilah turbin angin yang dibuat dari bahan dasar kayu (multiplek) dimodifikasi bagian tengah hingga bagian ujung belakang dengan menggunakan styrofoam, seperti yang terlihat di Gambar 5. Dengan modifikasi ini, diharapkan dapat mencegah overspeed pada generator dan memusatkan kerusakan di bagian bilah yang terbuat dari styrofoam akibat gaya dorong saat kecepatan angin cukup tinggi. Jika uji lapangan berhasil, maka pemusatan letak kegagalan bilah akan meminimalisir kerusakan (patahnya) bilah di bagian yang tidak terprediksi.

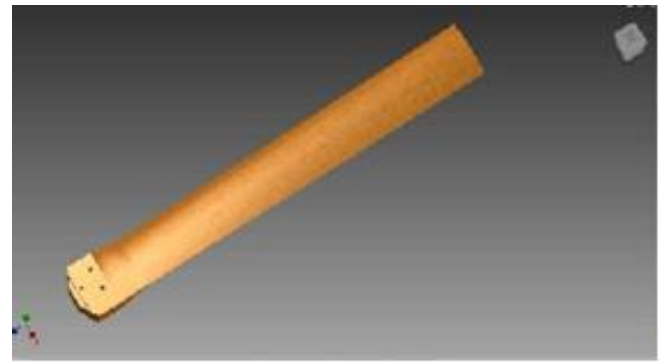

(a)

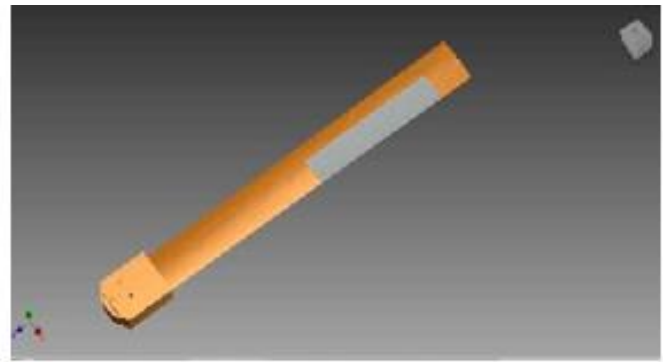

(b)

Gambar 5. Modifikasi bilah taperless $1 \mathrm{~m}$ menggunakan styrofoam sebelum (a) dan setelah (b) modifikasi

\section{B. Pembuatan Bilah Turbin Angin}

Tahap pertama yang dilakukan dalam pembuatan bilah turbin angin ini adalah pembuatan pola. Selanjutnya multiplek dipotong sesuai dengan pola yang telah dibuat dengan menggunakan mesin scroll saw. Hasil pemotongan pola dihaluskan lagi dengan menggunakan mesin sander, seperti yang terlihat pada Gambar 6.

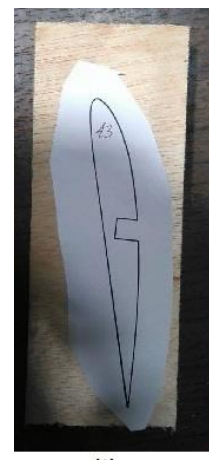

(1)

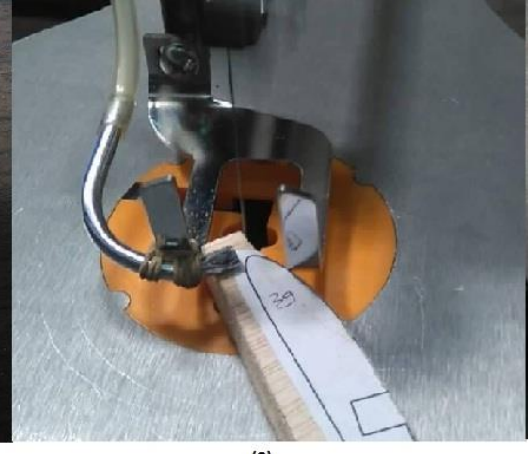

(2)

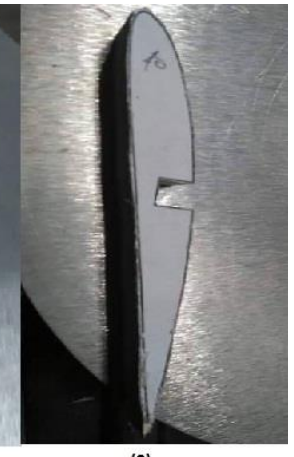

(3)

Gambar 6. Proses pemotongan pola penampang bilah turbin angin 
Selanjutnya multiplek dipasangkan ke main bar yang terbuat dari besi kotak pejal ukuran $8 \mathrm{~mm} \times 8 \mathrm{~mm}$. Bahan pola yang terbuat dari kayu dan batang utama yang terbuat dari baja, disatukan dengan menggunakan perekat berbahan cyanoacrylate, seperti yang terlihat di Gambar 7.

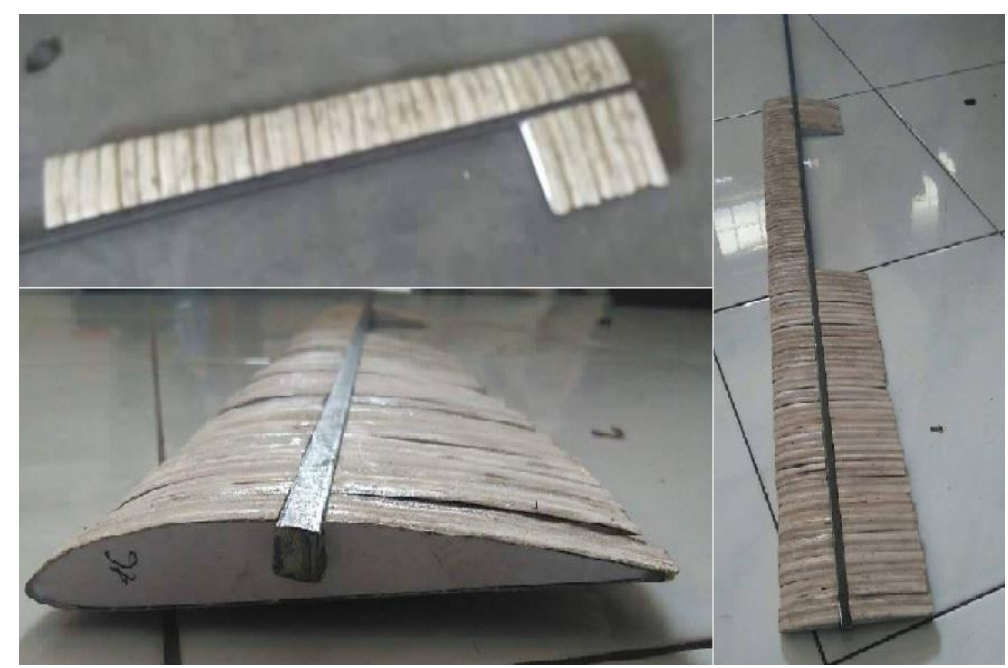

Gambar 7. Pemasangan pola menjadi bilah turbin angin

Styrofoam yang telah dipotong menggunakan hot wire cutter ditempelkan dengan menggunakan perekat kayu berbahan dasar PVaC. Pada tahap akhir, bilah turbin dilapisi kertas stiker berbahan dasar PVC (biasa digunakan untuk aksesori otomotif) dengan bantuan hot gun untuk melindungi permukaan bilah. Gambar 8 merupakan hasil akhir bilah turbin angin yang telah dilapisi stiker berbahan dasar PVC.

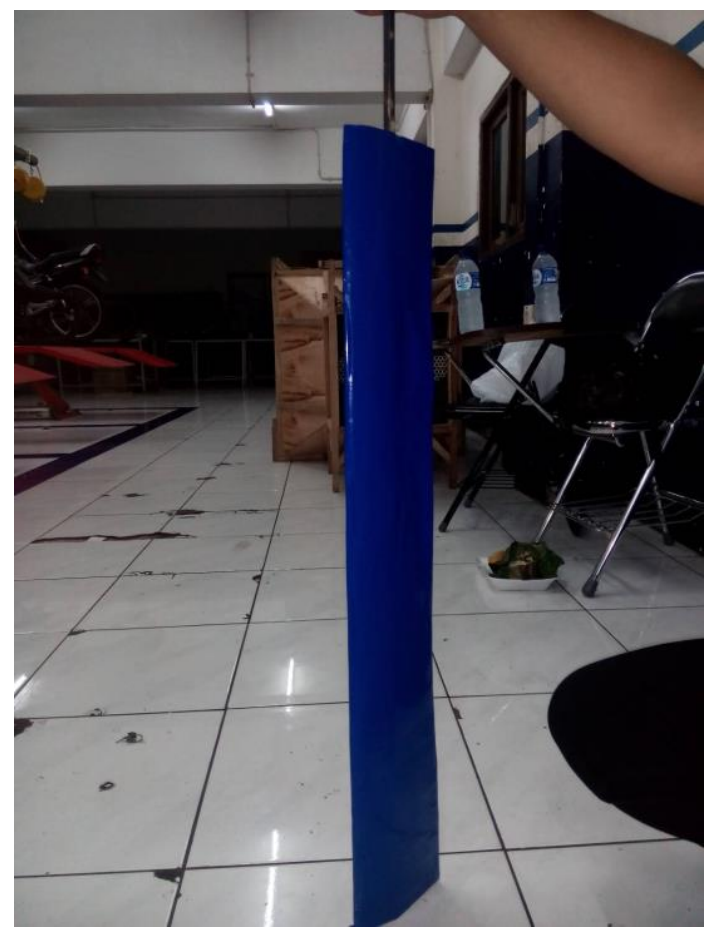

Gambar 8. Hasil akhir bilah turbin angin

\section{Hasil dan Pembahasan}

Tujuan dari penelitian ini adalah membuat bilah turbin angin dengan menggunakan bahan kayu dan styrofoam agar pada kecepatan tertentu bilah dapat rusak. Kerusakan akan dipusatkan pada bagian styrofoam yang memiliki tingkat ketahanan pembebanan lebih rendah dibandingkan dengan kayu. Nantinya kerusakan bilah tersebut akan melindungi generator agar tidak mengalami overspeed.

Bilah turbin angin yang dibuat dalam penelitian ini adalah tipe taperless, dimana ukuran bilah sama dari pangkal hingga ujung bilah. Tipe bilah taperless ini dipilih karena proses pembuatannya lebih mudah. Bilah diberi sedikit puntiran untuk mengoptimalkan nilai CP (power coefficient). 
Peranan bilah sebagai penangkap angin membuat bilah menjadi komponen penting dalam Pembangkit Listrik Tenaga Angin/Bayu. Bila kecepatan angin tinggi, maka bilah akan memutar rotor dengan cepat pula. Hal tersebut dapat mengakibatkan terjadinya overspeed pada generator. Untuk menghindari hal tersebut, dirancanglah bilah turbin angin dengan modifikasi styrofoam.

Kayu memiliki kekuatan dan kekakuan yang tinggi. Namun memiliki densitas yang rendah. Selain itu, kayu mudah didapat. Styrofoam pun memiliki densitas yang rendah dan mudah didapat. Styrofoam dipilih sebagai material modifikasi untuk pembuatan bilah turbin angin ini karena memiliki ketahanan pembebanan di bawah kayu. Styrofoam dikenal sebagai material yang getas dan mudah patah.

Styrofoam merupakan nama dagang dari expandable polystyrene (EPS) yang tersusun dari $5 \%$ polystyrene (PS) dan 95\% udara. Pada umumnya, styrofoam digunakan sebagai isolator dan bahan kemasan untuk peralatan listrik rumah tangga [11].

Modifikasi material bilah turbin dilakukan berdasarkan hasil simulasi performa bilah turbin angin dengan menggunakan perangkat lunak QBlade. Dari hasil simulasi ditunjukkan bahwa harga torsi total terbesar berasal dari torsi elemental dari bagian bilah pada posisi 50 - $100 \%$ panjang bilah. Berdasarkan hasil simulasi performa bilah turbin tersebut, maka dibuatlah bilah turbin dari bahan kayu yang dimodifikasi dengan menggunakan styrofoam pada bagian tengah hingga bagian ujung belakang bilah. Bagian ujung depan tetap menggunakan kayu untuk mempertahankan bentuk bilah dan aliran angin. Bagian tengah hingga ujung belakang dimodifikasi dengan menggunakan styrofoam karena styrofoam memiliki sifat kelelahan lebih besar dibandingkan dengan kayu. Dengan begitu, diharapkan dengan modifikasi material tersebut akan dapat mencegah overspeed pada generator dan memusatkan kerusakan di bagian bilah yang terbuat dari styrofoam akibat gaya dorong saat kecepatan angin cukup tinggi.

Bahan pola yang terbuat dari kayu dan batang utama yang terbuat dari baja, disatukan dengan menggunakan perekat berbahan cyanoacrylate. Perekat ini cukup kuat menahan pola agar tidak bergeser. Namun pada tahap pengeringan membutuhkan waktu yang cukup lama, sehingga rentang waktu pemasangan antar pola pun relatif lama, sekitar $30-60$ detik per pola.

Styrofoam ditempelkan pada pola dengan menggunakan perekat kayu berbahan dasar PVAc (polyvynil acetate). Perekat ini cukup kuat menahan geseran styrofoam, tetapi tidak tahan air. Untuk melindungi bilah dari cuaca (hujan dan panas), maka bilah dilapisi stiker berbahan dasar PVC yang biasa digunakan untuk aksesori otomotif. Stiker ini diharapkan dapat menahan air agar tidak masuk ke dalam bilah. Pemasangan stiker ini dilakukan dengan menggunakan bantuan hot gun. Hal ini dilakukan agar kontur stiker dapat mengikuti kontur bilah turbin. Selain itu, proses pemanasan dengan hot gun akan menambah sifat kekakuan stikernya.

\section{Kesimpulan}

Bilah turbin angin memiliki peranan penting dalam Pembangkit Listrik Tenaga Angin/Bayu. Struktur dan material bilah menentukan daya/keluaran yang dapat dihasilkan oleh PLTB. Bilah turbin angin yang dibuat dari kayu dimodifikasi dengan menggunakan styrofoam pada bagian tengah hingga ujung belakang bilah. Harapannya modifikasi tersebut dapat mencegah terjadinya overspeed pada generator dan memusatkan kerusakan di bagian bilah yang terbuat dari styrofoam akibat gaya dorong saat kecepatan angin cukup tinggi. Jika uji lapangan berhasil, maka pemusatan letak kegagalan bilah akan meminimalisir kerusakan (patahnya) bilah di bagian yang tidak terprediksi.

Proses pembuatan pola sangat menentukan kualitas akhir bilah. Penggunaan perekat cyanoacrylate dan PVAc selama proses pembuatan memberikan kekuatan yang cukup untuk menahan geseran. Namun untuk kondisi menahan beban dinamis dari angin, masih perlu diuji. Penambahan lapisan stiker PVC di bagian luar menambah kekuatan secara signifikan. Hal ini dikarenakan stiker tersebut menjadi penghantar beban antar pola, sehingga seluruh pola akan bekerja secara bersama-sama dalam menahan beban. Selain itu, stiker PVC pun menambah daya tahan bilah terhadap air.

\section{Ucapan Terima Kasih}

Terima kasih kepada Lembaga Penelitian dan Pengabdian Masyarakat (LPPM) Universitas Jenderal Achmad Yani yang telah membiayai penelitian ini. Terima kasih pula kami ucapkan kepada lembaga penelitian Lentera Angin Nusantara yang telah mendukung penelitian ini.

\section{Referensi}

[1] “windPROSPECTING." [Online]. Available: http://indonesia.windprospecting.com/. [Accessed: 26-Mar-2019].

[2] M. A. Ikaningsih and D. B. Saefudin, "Pemodelan Kekuatan Bilah Turbin Angin Horisontal Multimaterial," J. Tek. Media Pengemb. Ilmu dan Apl. Tek., vol. 17, pp. 27-35, 2018.

[3] C. K. Sekhar A், N. G. Kumar Ȧ, and B. G. Reddy Ȧ Ȧ, "Design of Blade for a Wooden Small scale wind turbine for domestic purpose," Int. J. Curr. Eng. Technol., vol. 44, no. 33, 1309.

[4] M. S. S, "Fatigue Failure Analysis of Small Wooden Wind Turbine Blade," Int. J. Comput. Eng. Res., vol. 3, no. 2, pp. 2250-3005, 2013.

[5] Sudarsono, "Kajian Sifat Mekanik Material Komposit Propeler Turbin angin Standard NACA 4415 Modifikasi," Pros. Semin. Nas. Apl. Sains dan Teknol., 2012.

[6] Y. C. T. and C. Y. S. R.R.Chang, T.H.Chiang, "Normalization Process Technique of Composite Foam-filled 
Sandwich Wind Turbine Blades," Procedia Eng., vol. 14, pp. 1988-1995, 2011.

[7] S. Jupp, "Alumunium as a Viable Solution for Offshore Wind Turbine," Deep Sea Offshore RnD Semin., 2011.

[8] P. Simanjuntak, "Blade Taperless 1 m," Tasikmalaya, 2015.

[9] D. Marten, J. Wendler, G. Pechlivanoglou, C. N. Nayeri, and C. O. Paschereit, "QBlade: An Open Source Tool For Design And Simulation of Horizontal and Vertical Axis Wind Turbines," Int. J. Emerg. Technol. Adv. Eng. An ISO Certif. Int. J., vol. 3, no. 9001, pp. 264-269, 2013.

[10] M. Hatta and A. Martin, "Perancangan Bilah Tipe Inverse Taper pada Turbin Angin Berdasarkan Kondisi Angin di Pekanbaru," Jom FTEKNIK, vol. 4, no. 1, 2017.

[11] A. N. Siyal, S. Q. Memon, and M. Y. Khuhawar, "Recycling of styrofoam waste: synthesis, characterization and application of novel phenyl thiosemicarbazone surface," Pol. J. Chem. Tech. Polish J. Chem. Technol., vol. 14, no. 10, pp. 10026-12, 2012. 